Cornell Law Library

Scholarship@Cornell Law: A Digital Repository

Cornell Law Faculty Publications

Faculty Scholarship

$1-1-2000$

\title{
Inbreeding in Law School Hiring: Assessing the Performance of Faculty Hired from Within
}

Theodore Eisenberg

Cornell Law School, ted-eisenberg@lawschool.cornell.edu

Martin T. Wells

Cornell University,mtw1@cornell.edu

Follow this and additional works at: http://scholarship.law.cornell.edu/facpub

Part of the Applied Statistics Commons, Legal Education Commons, and the Legal Profession Commons

\section{Recommended Citation}

Eisenberg, Theodore and Wells, Martin T., "Inbreeding in Law School Hiring: Assessing the Performance of Faculty Hired from Within" (2000). Cornell Law Faculty Publications. Paper 375.

http://scholarship.law.cornell.edu/facpub/375

This Article is brought to you for free and open access by the Faculty Scholarship at Scholarship@Cornell Law: A Digital Repository. It has been accepted for inclusion in Cornell Law Faculty Publications by an authorized administrator of Scholarship@Cornell Law: A Digital Repository. For more information, please contact jmp8@cornell.edu. 


\title{
INBREEDING IN LAW SCHOOL HIRING: ASSESSING THE PERFORMANCE OF FACULTY HIRED FROM WITHIN
}

\author{
THEODORE EISENBERG and MARTIN T. WELLS*
}

\begin{abstract}
This study compares the scholarly impact of inbred entry-level law school faculty members with the scholarly impact of noninbred entry-level law school faculty members. The sample includes 32 law schools and approximately 700 entry-level faculty members. By our measure of performance, scholarly impact as measured by citation frequency, inbred entry-level law school faculty members do not perform as well as noninbred entry-level faculty members.
\end{abstract}

L Aw school faculty hiring is rational in at least two respects. First, one's chance of being initially hired by an elite law school correlates positively with the strength of one's credentials. ${ }^{1}$ Second, one's chance of being laterally hired correlates positively with one's scholarly impact. ${ }^{2}$ The greater one's scholarly impact, the more likely one will have been hired by at least one school after one's initial faculty position. Both results are consistent with using available information to filter faculty candidates. More information improves hiring, and the information is used in the expected manner.

A positive relation between information about candidates and hiring decisions ought to manifest itself especially strongly in hiring one's own graduates. After all, faculties have the best possible information about their own

* Eisenberg is Henry Allen Mark Professor of Law, Cornell Law School. Wells is professor, Department of Social Statistics, Cornell University. We would like to thank Kevin M. Clermont and Ronald G. Ehrenberg for their comments.

1 Deborah Jones Merritt \& Barbara F. Reskin, Sex, Race, and Credentials: The Truth about Affirmative Action in Law Faculty Hiring, 97 Colum. L. Rev. 199, 240 (1997). "[E]lite schools stressed many of the credentials traditionally assumed to influence law faculty hiring. Graduation from a prestigious college and law school, experience as a Supreme Court clerk, and possession of a doctoral degree in a field other than law all significantly increased the likelihood that a professor would teach at an elite law school."'

2 Theodore Eisenberg \& Martin T. Wells, Ranking and Explaining the Scholarly Impact of Law Schools, 27 J. Legal Stud. 373, 412 (1998).

[Journal of Legal Studies, vol. XXIX (January 2000)]

(C) 2000 by The University of Chicago. All rights reserved. 0047-2530/2000/2901-0016\$01.50 
graduates. There should be less difficulty in making comparisons with other graduates of one's own school. Several professors are likely to be personally familiar with a candidate's performance in class, in written assignments, as a research assistant, and in informal interactions. This information will have been gathered over a period of 3 years. In comparison, when hiring graduates of other law schools, one usually depends on a written transcript, references of varying reliability, 1 day of interviews, an oral presentation, and perhaps an article or manuscript.

In hiring our own, law schools truly should be getting the cream of the crop. At a minimum, they should be getting faculty members who perform as well as faculty members hired from other schools. Whatever a school's hiring standard, the school ought to be able to apply it as well to its own graduates as to graduates of other schools. The information-based view of hiring suggests that it would be remarkable if the collective legal academy does a poorer job of hiring those with whom we are most familiar.

Yet that is the case. This article compares the performance of faculty members first hired by the law schools from which they graduated with the performance of faculty members initially hired by law schools from which they did not graduate. For ease of reference, we refer to the former group as "inbred." As measured by citations to their work, inbred faculty members at the 32 law schools studied here have significantly less scholarly impact than noninbred faculty members.

Despite the information-based argument sketched above, no one seems surprised by this result. Decision makers seem ready to acknowledge that their biases will compromise the quality of candidates hired from within. Indeed, many high-quality doctoral programs, with some empirical support, ${ }^{3}$ have absolute or near-absolute rules against providing their doctoral students with their first tenure-track appointment. Those programs suspect what we find: that inbreeding compromises faculty quality. Biases in processing information about those close to us overwhelm informational advantages that exist about one's own graduates to produce a group of faculty members with less scholarly impact. Section I describes the methodology used. Section II presents our results.

\section{Methodology and BaCKground Considerations}

Comparing the scholarly impact of inbred and noninbred faculty members requires a measure of scholarly impact. This article uses a measure of

${ }^{3}$ Peter M. Blau, The Organization of Academic Work 137-38 (1973); Donna Fossum, Women Law Professors, 1980 Am. B. Found. Res. J. 903, 909-11; Lowell L. Hargens \& Grant M. Farr, An Examination of Recent Hypotheses about Institutional Inbreeding, $78 \mathrm{Am}$. J. Soc. 1381 (1973); Merritt \& Reskin, supra note 1, at 223 n.82 (collecting studies). 
performance-citations to a scholar's work - that we developed earlier. The methodology used is described in detail elsewhere ${ }^{4}$ and is therefore only briefly summarized here.

\section{A. Defining Inbred Faculty Members and a Comparison Group}

We define a faculty member to be inbred when the faculty member's first full-time, tenure-track, U.S. law school teaching position is at the school from which the faculty member received a J.D. or LL.B. degree. Faculty members who started teaching at schools other than their J.D. school are not treated as inbred even if they eventually return to their J.D. school.

For some purposes, it is useful to distinguish between two groups of inbred faculty. Some inbred faculty members are no longer at the school that first hired them. They were initially inbred but have since moved to other schools. The move could be a positive development, such as being hired by a superior law school, or a negative development, such as going to another law school after a tenure denial. Fully measuring inbred faculty members' performance requires accounting for inbred hires that move to other schools. Failure to do so could distort evaluation of schools' hiring of their own graduates. For example, suppose that school $\mathrm{X}$ hires several of its own graduates who are highly successful scholars and several who are unsuccessful. The successful scholars are hired away by other schools, leaving a set of weaker scholars at school X. If one just looks at the set of weaker scholars remaining at school X, one would understate school X's performance in evaluating its own graduates. So sometimes we look at all entrylevel hires.

But, in another perspective, one may want to limit the focus to scholars remaining at school $X$. This is, after all, the net result of their entry-level hiring process. Schools that weed out weak inbred entry-level hires should not have those hires count against their entry-level hiring performance. For example, suppose school $\mathrm{X}$ denies tenure to its weak inbred scholars and manages to keep its strong inbred scholars on its permanent faculty. Schools that weed out weak inbred performers produce a net hiring pattern of inbred scholars that could be quite strong. In this perspective, one should focus on those inbred scholars remaining at school $\mathrm{X}$ and not count against school X's inbred account the weaker group of scholars whom school X has not retained but that may still be teaching at other institutions.

In a similar manner, one should also account for the possibly temporary status of entry-level hires who lack tenure. For a range of about 5-7 years at the beginning of a career, one cannot be sure whether a faculty member

${ }^{4}$ Eisenberg \& Wells, supra note 2, at 376-86. 
will stay at the school. Analysis of a more stable population, those in teaching more than 7 years, avoids effects attributable to possibly temporary faculty. We therefore limit our sample to faculty members in teaching more than 7 years. This also assures that each faculty member studied will have had a substantial period of time in which to perform and to have had scholarly impact. We are in effect treating faculty members as permanently part of their faculties after 7 years of teaching rather than at the instant of hiring.

With whom should inbred hires be compared? The obvious group consists of other entry-level hires at the same school. One could include laterally hired faculty members at the same school in the comparison group. But decision making about lateral hires usually is based on better information than is decision making about entry-level hires. One has information about lateral hires' actual scholarly performance. We thus limit the sample to those faculty members not hired laterally except when we follow an inbred faculty member's path if the faculty member leaves his or her entry-level school. Including laterally hired faculty would increase the strength of the inbred effect we report.

\section{B. Data}

Comparing performance of inbred and noninbred faculty members requires a basis for comparison. As in our prior work, we use citations to faculty members as a measure of scholarly impact. ${ }^{5}$ West Publishing Group's Westlaw texts and periodicals database, referred to on-line as TP-ALL, is the database used to measure citations. It contains works from hundreds of journals and other sources. We use the following query for each faculty member at each school in the study: "first_name w/2 last_name." Westlaw reports the number of documents in which the search term appears. This Westlaw response is the number used in this study. ${ }^{6}$ We adjust this number to account for different search dates and the fact that Westlaw grows over time. ${ }^{7}$

One also must specify the groups of faculty members to be included in

\footnotetext{
${ }^{5}$ Another useful measure of the success of new hires would be the proportion of new hires who get tenure at the initial hiring institution or at one of equal or higher quality. One could test whether being inbred is a useful predictor of the tenure outcome. See Ronald G. Ehrenberg, Paul J. Pieper, \& Rachel A. Willis, Do Economics Departments with Lower Tenure Probabilities Pay Higher Faculty Salaries? 80 Rev. Econ. \& Stat. 503 (1998), which explores the relation between salary level and tenure probability. Our impression is that strong law schools are less likely to deny tenure than other strong departments and that a larger sample may be needed to explore this measure meaningfully.

${ }^{6}$ For discussion of the limitations of the search used, see Eisenberg \& Wells, supra note 2 , at $379-85$.

${ }^{7}$ Id. at $384-85$.
} 
the study. Adjunct professors, administrators, legal writing instructors, librarians, and deans (one per school but not associate deans who are faculty members) as well as laterally hired faculty members are not included in the study. We also exclude faculty members who lack a J.D. or LL.B. degree from a U.S. law school. Such faculty members cannot have been inbred in the sense we use the term here. We include lateral hires only when accounting for inbred faculty members who have moved to other schools and then include only such inbred faculty members.

Subject to the above exclusions, the faculty members searched at each school consist of those appearing in the Association of American Law Schools Directory of Law Teachers for the 1993-94 academic year (the AALS Directory). As discussed above, we control for length of time in teaching by limiting the results to those with more than 7 years of teaching experience. We further control for length of time in teaching by analyzing performance on the basis of citations adjusted to reflect a faculty member's years in teaching. We do not account for post-1994 movement of faculty members. ${ }^{8}$ For 75 professors in this study, the AALS Directory indicates the law school at which they are currently teaching but does not expressly show the law school of initial hiring. Individual analysis of these entries showed these professors almost always to have been initially hired by the school at which they are listed as currently teaching, and we so treat them. We have repeated our analyses by excluding these professors from the analysis, and the results do not materially change from the results reported here. ${ }^{9}$ Information about a few professors is missing from the AALS Directory. They are not included in the study.

The sampling methodology yields a sample of 128 inbred entry-level faculty members who continue to teach at their school of initial hire, 511 noninbred entry-level faculty members, and 24 inbred faculty members who left their original school of hire. As shown below, inbred status varies

${ }^{8}$ Our earlier study reports the criteria for including schools in the study. "We include all schools that U.S. News \& World Report's 1996 ranking of law schools lists as being in the top 20 in academic reputation. Our selection of the 12 additional schools is eclectic."'Eisenberg \& Wells, supra note 2 , at 379 . We again emphasize that we have not systematically identified the top 32 schools.

9 In our prior study, the absence of an express match between current school and school of initial hiring resulted in these 75 professors being treated as lateral hires. Treating them as entry-level hires, which we now believe to be more accurate, mildly increases the differences between lateral and entry-level hires. We previously reported mean time-adjusted entry-level citations of 0.98 for entry-level hires and 1.06 for lateral hires and median timeadjusted citations of 1.02 for entry-level hires and 1.10 for lateral hires. Eisenberg \& Wells, supra note 2 , at 403 , table 6 . Characterizing these 75 professors as entry-level hires results in no change in the entry-level mean and median. It increases the lateral hire mean to 1.07 and the lateral hire median to 1.11 . In addition, the overall percentage of lateral hires would drop from 39.6 percent to 32.6 percent, and some individual school results would vary. 
widely from school to school, so our analysis emphasizes school-level results as well as sample-wide results.

One possible bias in the sample should be noted. As an ideal, we would like data on all entry-level hires at each school in the sample to enable us to compare citations later in the careers of inbred and noninbred hires. Our sample is derived from a cross section (as of 1993-94) of law school faculty members, not from following the performance of every entry-level hire regardless of the year of hire. In particular, entry-level hires who left law school teaching or moved to a school not in our sample of 32 schools before our cross-sectional data were collected will not appear in our sample. If such faculty members were scholars with low citation frequencies who were also disproportionately noninbred hires, then our analysis will overstate the productivity of noninbred entry-level hires. In contrast, if those who left teaching or left sample schools had low citation frequencies and were disproportionately inbred hires, then our analysis will understate the relative productivity of noninbred hires.

Limiting the study to those in teaching more than 7 years cushions this possible bias. We are primarily interested in those who survived the tenure process, not in those who were hired and soon departed. Any inbred effect is arguably less interesting if it disappears among the tenured faculty. Entry-level hires who left law teaching or moved to nonsample schools fewer than 8 years into their careers would not appear in our sample anyway. So only those who left law teaching or moved to nonsample schools after more than 7 years of teaching and before our sample period, presumably after receiving tenure, would be excluded.

\section{RESUlts}

We first explore the characteristics of inbred faculty and then compare their performance with that of noninbred faculty.

\section{A. Who Is Inbred?}

Inbreeding should be a proxy for the quality of a school's graduates. The very best schools should do the most inbreeding, and existing evidence suggests that they do. ${ }^{10}$ In the extreme, if all the best law school graduates came from one school, the best schools should be disproportionately populated by that school's graduates. Lesser schools should also value the best school's

${ }^{10}$ Merritt \& Reskin, supra note 1, at 242-43, 248-49; Robert J. Borthwick \& Jordan R. Schau, Note, Gatekeepers of the Profession: An Empirical Profile of the Nation's Law Professors, 25 U. Mich. J. L. Reform 191, 231 (1991). Borthwick and Schau report that 35 percent of faculty at top-seven schools were inbred compared to 15 percent in a random sample of 872 law professors. 
TABLE 1

Proportion of Faculties That Are Inbred

\begin{tabular}{lccccc}
\hline \hline & $\begin{array}{c}\text { No. of } \\
\text { Entry-Level } \\
\text { Inbred } \\
\text { Hires }\end{array}$ & $\begin{array}{c}\text { No of. } \\
\text { Entry-Level } \\
\text { Noninbred } \\
\text { Hires }\end{array}$ & $\begin{array}{c}\text { Proportion } \\
\text { of Inbred } \\
\text { Entry-Level } \\
\text { Faculty }\end{array}$ & $\begin{array}{c}\text { Faculty } \\
\text { Teaching } \\
\text { > 7 Years }\end{array}$ & \begin{tabular}{c}
$\begin{array}{c}\text { Proportion of } \\
\text { Inbred Faculty } \\
\text { Teaching } \\
>7 \text { Years }\end{array}$ \\
\hline Berkeley
\end{tabular} \\
Chicago & 6 & 22 & .21 & 34 & .18 \\
Columbia & 3 & 8 & .27 & 18 & .17 \\
Georgetown & 13 & 15 & .46 & 45 & .29 \\
Harvard & 8 & 30 & .21 & 63 & .13 \\
Michigan & 26 & 6 & .81 & 45 & .58 \\
NYU & 7 & 14 & .33 & 35 & .20 \\
Stanford & 8 & 20 & .29 & 47 & .17 \\
Virginia & 4 & 12 & .25 & 32 & .13 \\
Wisconsin & 8 & 15 & .35 & 40 & .20 \\
Yale & 6 & 19 & .24 & 35 & .17 \\
Other 21 schools & 11 & 4 & .73 & 31 & .35 \\
$\quad$ Total & 28 & 346 & .07 & 592 & .05 \\
\hline
\end{tabular}

SourCE.-Association of American Law Schools, Directory of Law Teachers, 1993-1994 (1993).

NOTE.-Only faculty members with U.S. law school J.D. or LL.B. degrees teaching more than 7 years are included. Inbred faculty members who have moved to other schools are not treated as inbred. Faculty members who do not have U.S. J.D. or LL.B. degrees are also excluded, as they do not satisfy our definition of inbred.

graduates over their own graduates, thereby reducing the inbreeding rate at lower ranked schools. Table 1 shows the percent of a school's entry-level hires that are inbred. It does not count as inbred those entry-level hires who subsequently moved to other schools. It is a snapshot of each faculty's percentage of inbred entry-level hires, accounting for the fact that some inbred hires may have left. We report the results for each school with a substantial percentage of inbred faculty members. We treat all other schools as a single residual category.

Looking solely at entry-level hires, Harvard and Yale are the most substantially inbred faculties. Their strong student bodies should support an above average degree of inbreeding. But the proportion of inbred entrylevel hires is incomplete as a measure of the degree to which faculty is inbred. This is because entry-level hires make up very different proportions of schools' faculty. Harvard's and Yale's entry-level inbreeding rates of .81 and .73 , respectively, are not so different for entry-level hires. But their rates of entry-level hiring differ dramatically. Harvard's faculty includes about 25 percent lateral hires, and Yale's includes more than 50 percent lateral hires. ${ }^{11}$ Thus Harvard's high rate of entry-level inbreeding, combined

1 Eisenberg \& Wells, supra note 2, at 403, table 6. 


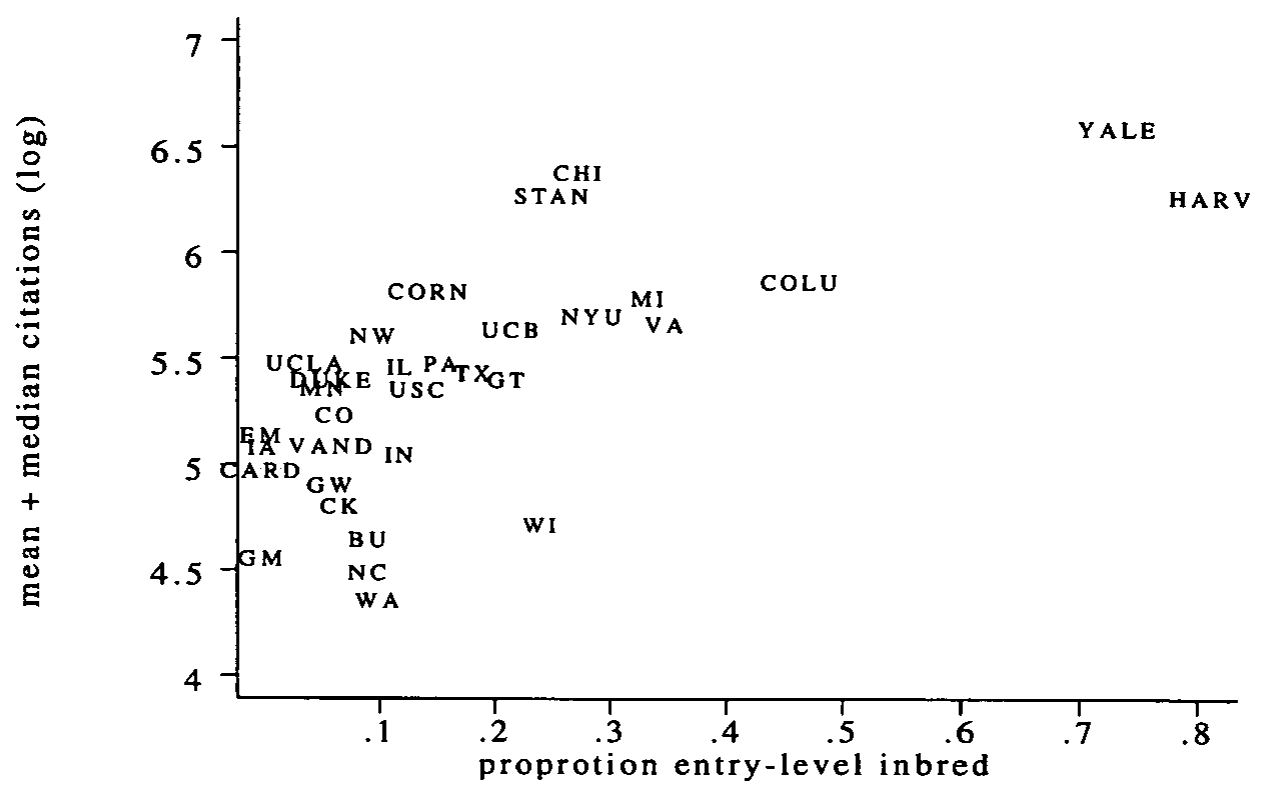

FIGURE 1.-Relation between schools' scholarly impact and proportion of entry-level faculty that is inbred. Inbred faculty members who have moved to other schools are not counted as inbred in the figure. Sources: Westlaw TP-ALL database and the Association of American Law Schools, Directory of Law Teachers, 1993-1994 (1993).

with its low rate of lateral hiring, leaves it substantially more inbred than Yale. The last column of Table 1 illustrates this, showing that Harvard's faculty, now including lateral hires with more than 7 years in teaching, ${ }^{12}$ is almost 60 percent inbred whereas Yale's faculty is 35 percent inbred. Accounting for lateral faculty members also shows that Columbia is almost as inbred as Yale.

We find a strong correlation between inbreeding and a school's overall scholarly impact. Figure 1 suggests the strength of the correlation between a school's scholarly impact and the proportion of its faculty that is inbred. Its $x$-axis is the proportion of a school's entry-level hires that are inbred. The $y$-axis is the logarithm of the sum of the median plus mean citations for the school's faculty - a measure of the school's scholarly impact. ${ }^{13}$ By this measure of scholarly impact, all of the eight most inbred schools perform well compared with other schools. But there are noteworthy differences in the relation between the degree of inbreeding and scholarly impact. Columbia, Michigan, and Virginia are more inbred at the entry level than

${ }_{12}$ This column continues to exclude faculty members lacking U.S. law school J.D. degrees, but including them would not materially change the results.

${ }^{13}$ Eisenberg \& Wells, supra note 2, at 388 , table 1. 


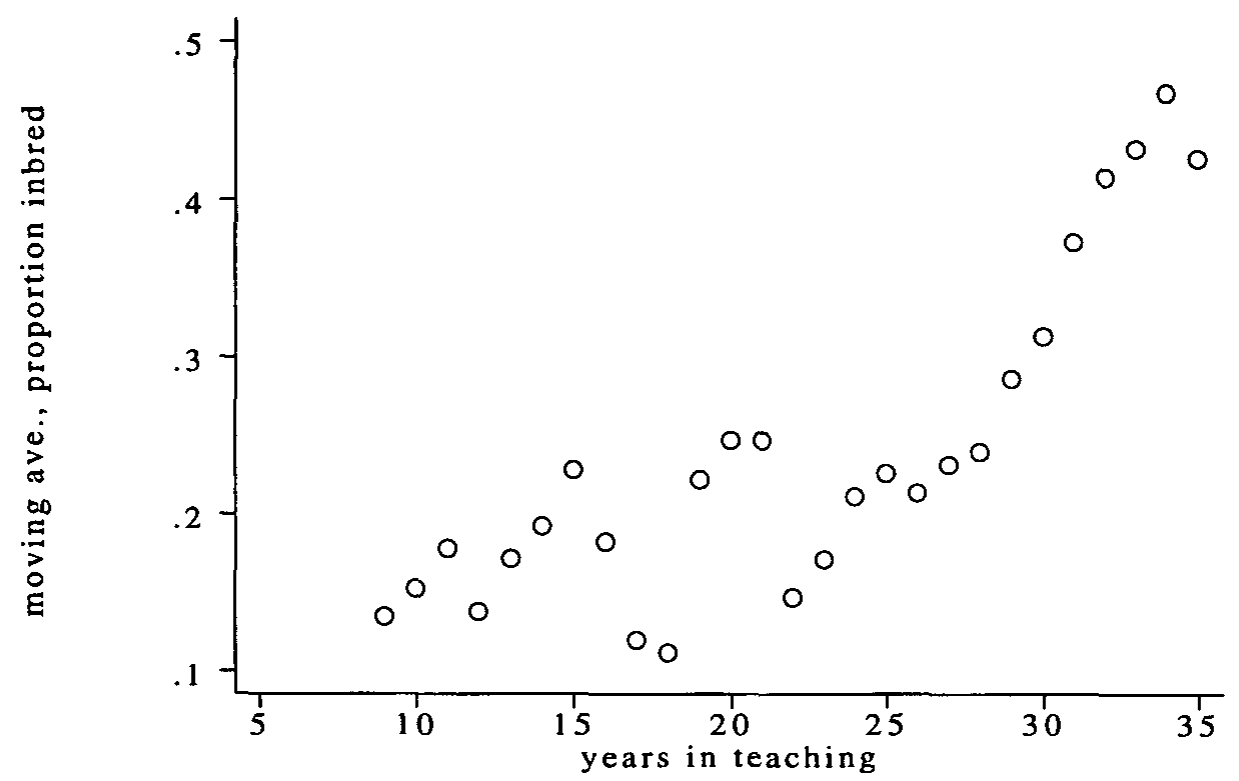

FiguRE 2.- The 3-year moving average of proportion of entry-level hires that are inbred. Inbred faculty members who have moved to other schools are counted as inbred in the figure. Source: The AALS Directory of Law Teachers, 1993-1994 (1993).

Stanford or Chicago, yet the three more inbred schools do not outperform Stanford or Chicago.

Inbreeding rates exhibit a noticeable time trend. The proportion of entrylevel faculty members who are inbred correlates positively with years of teaching experience. Inbreeding thus seems to be a diminishing phenomenon. Figure 2 displays the trend. It presents a 3-year moving average over time of the proportion of inbred entry-level faculty at the 32 schools. The moving average helps stabilize the year-to-year variation that can result from small numbers of hires in any given year. The time trend for the two most inbred schools, Harvard and Yale (not reported here), looks markedly different. Neither school yet shows a discernable long-term time trend toward less inbreeding.

The relations between inbreeding, race, and sex are time sensitive in that few female and minority faculty members were in law teaching more than 20 years ago. Table 2 therefore divides the sample of entry-level law professors into those in teaching more than 20 years and those in teaching between 8 and 20 years. (Recall that we exclude from the sample faculty members in teaching fewer than 8 years.) In both time periods, conditional on being hired, white female faculty members were more likely to be inbred than white male faculty members. But the differences in both periods are not statistically significant. For the group with more years in teaching, there were too few minority faculty members to allow for meaningful compari- 
TABLE 2

Race and Sex of Inbred Entry-Level Faculty over Time

\begin{tabular}{|c|c|c|c|c|c|c|}
\hline \multirow[b]{2}{*}{ RACE AND SEX } & \multicolumn{3}{|c|}{ 8-20 Years in Teaching } & \multicolumn{3}{|c|}{$\begin{array}{c}\text { More Than } 20 \text { Years in } \\
\text { Teaching }\end{array}$} \\
\hline & $\begin{array}{l}\text { Number } \\
\text { Inbred }\end{array}$ & $\begin{array}{l}\text { Number } \\
\text { Noninbred }\end{array}$ & $\begin{array}{l}\text { Proportion } \\
\text { Inbred }\end{array}$ & $\begin{array}{l}\text { Number } \\
\text { Inbred }\end{array}$ & $\begin{array}{l}\text { Number } \\
\text { Noninbred }\end{array}$ & $\begin{array}{l}\text { Proportion } \\
\text { Inbred }\end{array}$ \\
\hline White male & 35 & 204 & .15 & 83 & 189 & .31 \\
\hline White female & 18 & 68 & .21 & 8 & 12 & .40 \\
\hline Minority male & 1 & 10 & .09 & 1 & 1 & .5 \\
\hline Minority female & 6 & 20 & .23 & 0 & 7 & 0 \\
\hline Total & $\overline{60}$ & $\overline{302}$ & .17 & $\overline{92}$ & $\overline{209}$ & .31 \\
\hline
\end{tabular}

Source.-Association of American Law Schools, Directory of Law Teachers, 1993-1994 (1993).

NoTE.-Only entry-level hires with U.S. law school J.D. or LL.B. degrees are included. Inbred faculty members who have moved to other schools are not treated as inbred.

sons. For the less experienced group, minority males were less likely to be inbred and minority females more likely to be inbred than white males.

The male-female results in both periods may be surprising. The stereotypical "old boy" network should produce inbred faculty that are predominantly white and male. In a sense, this is true. The great majority of inbred faculty are white males. But faculties dominated by white males might be expected to reproduce themselves by hiring inbred white males in disproportion to total hires. This is not the case. If male decision makers disfavor female candidates, it is in the total number of female hires, not in the female proportion of inbred faculty members. ${ }^{14}$ In regression models we find that controlling for school and courses taught can help explain the pattern of inbred hiring. White female status is nearly a significant predictor ( $p=$ .055 ) of being inbred, but minority status is not.

\section{B. The Relation between Inbreeding and Scholarly Impact}

The best schools understandably do the most inbreeding. This suggests the need to control for the school at which someone is hired to isolate the effects of inbreeding. We do this by first comparing, on a school-by-school basis, the performance of inbred and noninbred entry-level hires.

We also need to control for the different experience levels of inbred and noninbred faculty members. Citations to a scholar's work relate to years in

${ }^{14}$ Evidence of discrimination in whether to extend a job offer to females is lacking. Merritt \& Reskin, supra note 1, at 233, 240-45. However, Merritt and Reskin find that the professorial rank of hiring correlates negatively with being a female. But see id. at 237 . 
teaching, and pairs of important groups have different mean periods of years in teaching. Entry-level hires and lateral hires, men and women, minorities and nonminorities all have different tenures for which comparisons of scholarly impact need to account. ${ }^{\text {is }}$ The same is true of inbred and noninbred faculty members. As suggested by Figure 2, inbreeding has a definite time trend. Inbred entry-level faculty members average about 24 years in teaching, whereas noninbred entry-level faculty members average about 19 years in teaching. Thus comparing their scholarly impact should account for this substantial time differential.

To provide rankings that control for differing experience levels of teachers, we elsewhere develop a time-adjusted measure of citations, which we also use here. The adjusted measure for each faculty member is the logarithm of the faculty member's citations, divided by the citations (log) of each faculty member's teaching experience cohort. ${ }^{16}$ Each faculty member thus is effectively compared only with faculty members with the same number of years in teaching. For all faculty members as a group, time-adjusted citations should have a mean of approximately 1.0. The mean for 1,292 entry-level and lateral faculty members is 1.01 , and the median is 1.05 . The mean for the entry-level faculty members used in this study is 0.98 . It is below the median and mean in the larger sample because of the exclusion of lateral hires. An alternative approach to dealing with different periods of teaching experience would be to divide citations by years in teaching. Our prior study indicates that this method is unsatisfactory. ${ }^{17}$

Table 3 presents the results. At all but two of the schools with substantial inbred faculty as well as in the residual category of 21 other schools, inbred entry-level faculty members have lower mean time-adjusted citations than noninbred entry-level faculty members. And at one of the two schools, the inbred and noninbred faculty members are tied. The story is similar for median time-adjusted citations, with only one school having an inbred median higher than the noninbred median. The results at three individual schoolsGeorgetown, Harvard, and Wisconsin-are significant or near significant. ${ }^{18}$ The overall pattern of inferior inbred performance is unmistakable.

How large is the inbred effect? This requires understanding our measure of time-adjusted citations. As noted above, this measure is the ratio of the

${ }^{15}$ Eisenberg \& Wells, supra note 2, at 401, table 5.

${ }^{16}$ For the method of estimating time-adjusted citations, see id. at 398-400.

${ }^{17}$ Id. at $405-6$ n.39.

${ }^{18}$ A Mann-Whitney two-sample test statistic of the entry-level inbred and noninbred faculty members yields the following $p$-values: Georgetown, $p=.001$; Harvard, $p=.004$; and Wisconsin, $p=.065$. See H. B. Mann \& D. R. Whitney, On a Test of Whether One of Two Random Variables Is Stochastically Larger than the Other, 18 Annals Mathematical Stat. 50 (1947). 


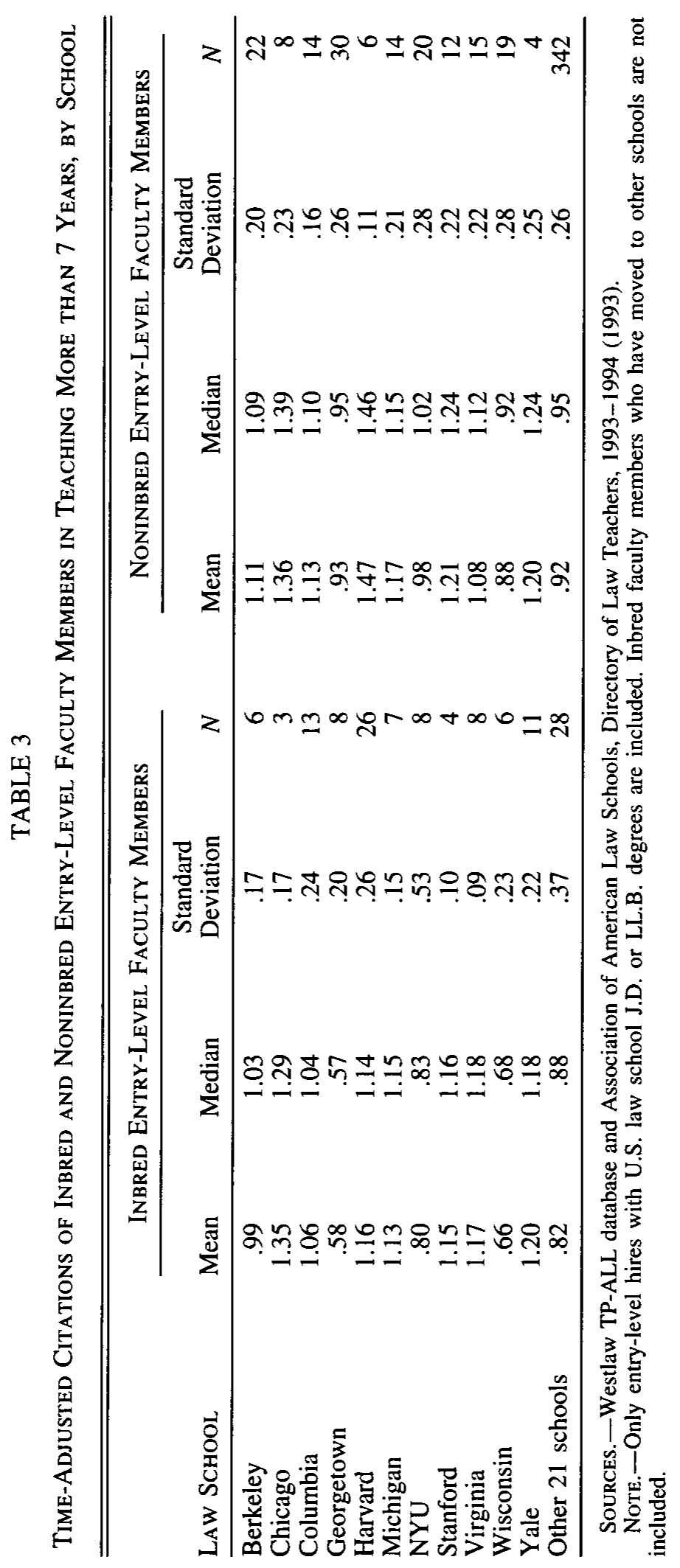


$\log$ of a faculty member's citations to the log of citations of a faculty member's teaching experience cohort. To illustrate, assume that a group with the same years of teaching experience as a particular faculty member has a mean of 100 citations to its work. Assume further that the faculty member has 160 citations to his or her work. The ratio of the logs of 160 and 100 is 1.10 . So for this level of citations, a 0.10 difference in time-adjusted cites translates into a 60 percent increase in citations over one's age cohort. Such a difference applied to an entire faculty would move a school one or two groups in our grouping of schools. ${ }^{19}$ The difference, and therefore the inbred effect, is not trivial. ${ }^{20}$

\section{Further Controls: Regression Analysis}

The importance of school effects in assessing inbred performance suggests the need for analysis that is deeper than the summary statistics in Table 3. And accounting for factors other than schools can test the robustness of the finding that inbred scholars perform relatively poorly as measured by scholarly impact.

Professors working in certain areas, especially tax, produce fewer articles and are cited less than teachers in other areas. ${ }^{21}$ In a similar manner, some areas, such as constitutional law and feminism, are amenable to increased productivity or citations. It may be that schools use inbred candidates to staff courses that are disfavored in measures of productivity or impact. The poor performance of inbred scholars may be an artifact of the areas in which they teach.

To control for areas of teaching and other factors, we rely on regression analysis. The dependent variable is time-adjusted citations, an index that accounts for faculty members' different years in teaching. The key explanatory variable of interest is the inbred dummy variable, which is equal to one if a faculty member was hired by the law school from which he or she graduated. We include a variable that measures the time delay before entering teaching, which has been shown to correlate negatively with scholarly im-

19 See Eisenberg \& Wells, supra note 2, at 388, table 1.

${ }^{20}$ Some schools have significant differences in the standard deviations between inbred and noninbred candidates: Harvard, $p=.033$; NYU, $p=.013$; and Virginia, $p=.014$. But the differences go in opposite directions at different schools. For example, Harvard's and NYU's inbred faculty members have higher standard deviations than their noninbred faculty members. But Virginia and most other schools show the opposite effect.

${ }^{21}$ Eisenberg \& Wells, supra note 2, at 409, table 7; Deborah Jones Merritt, Research and Teaching on Law Faculties: An Empirical Exploration, 73 Chi.-Kent L. Rev. 765, 783-85 (1998). 
pact. ${ }^{22}$ We include dummy variables for each school as well as for race and sex combinations.

Table 4 presents the results of three models. In the first model, we limit the inbreds to those who remain at the school of their original teaching job. This model assesses those inbreds who have not left their school and does not count as inbred those who were hired as inbred but have since moved to other schools. The second model includes all entry-level faculty in teaching more than 7 years. Inbred faculty members who leave their school of initial hire for another school in our group are included. The third model excludes Harvard from the sample in order to check whether the basic inbred finding is a consequence of Harvard's dominance of the inbred sample. ${ }^{23}$

Table 4 shows a significant, large negative relation between being inbred and scholarly impact. If we control for course, school, and the other factors, inbred faculty members are cited between 7 and 13 percent less than other faculty members. Since time-adjusted citations are measured as a ratio of logs, this could be viewed as understating the difference between inbred and noninbred faculty members. The -.081 coefficient in the second model translates to the difference between 145 and 100 citations, a 45 percent difference from one's baseline age cohort.

If one excludes Harvard from the sample-the school with the greatest number and percent of inbred faculty members-the third model in Table 4 shows that the inbred variable's coefficient does not materially change from the second model. Thus, although Harvard is the most inbred faculty, the gap between its inbred entry-level hires and its other entry-level hires is not strikingly different from the gap in other schools. If one excludes both Harvard and Yale, the two most inbred schools, the inbred variable's coefficient is $-.080(p<.01)$. The inbred effect is not a consequence of one or two schools' hiring practices.

Analysis of the residuals of our regression models shows that after controlling for school effects, citations to inbred faculty members exhibit significantly higher variance than do citations to noninbred faculty members. The combination of lower mean citations and higher variance suggests that faculties are not using their greater information about inbreds to lower the variance in scholarly impact. The low mean is not a trade-off for less variability.

${ }^{22}$ Eisenberg \& Wells, supra note 2, at 411 , table 8.

${ }^{23}$ In the regression models, one could account for differences in years of teaching experience by using citations (log) as the dependent variable and including variables representing years in teaching as explanatory variables. It takes at least cubic, and possibly quartic, terms to model citation frequency as effectively as does our adjusted citations-dependent variable. 


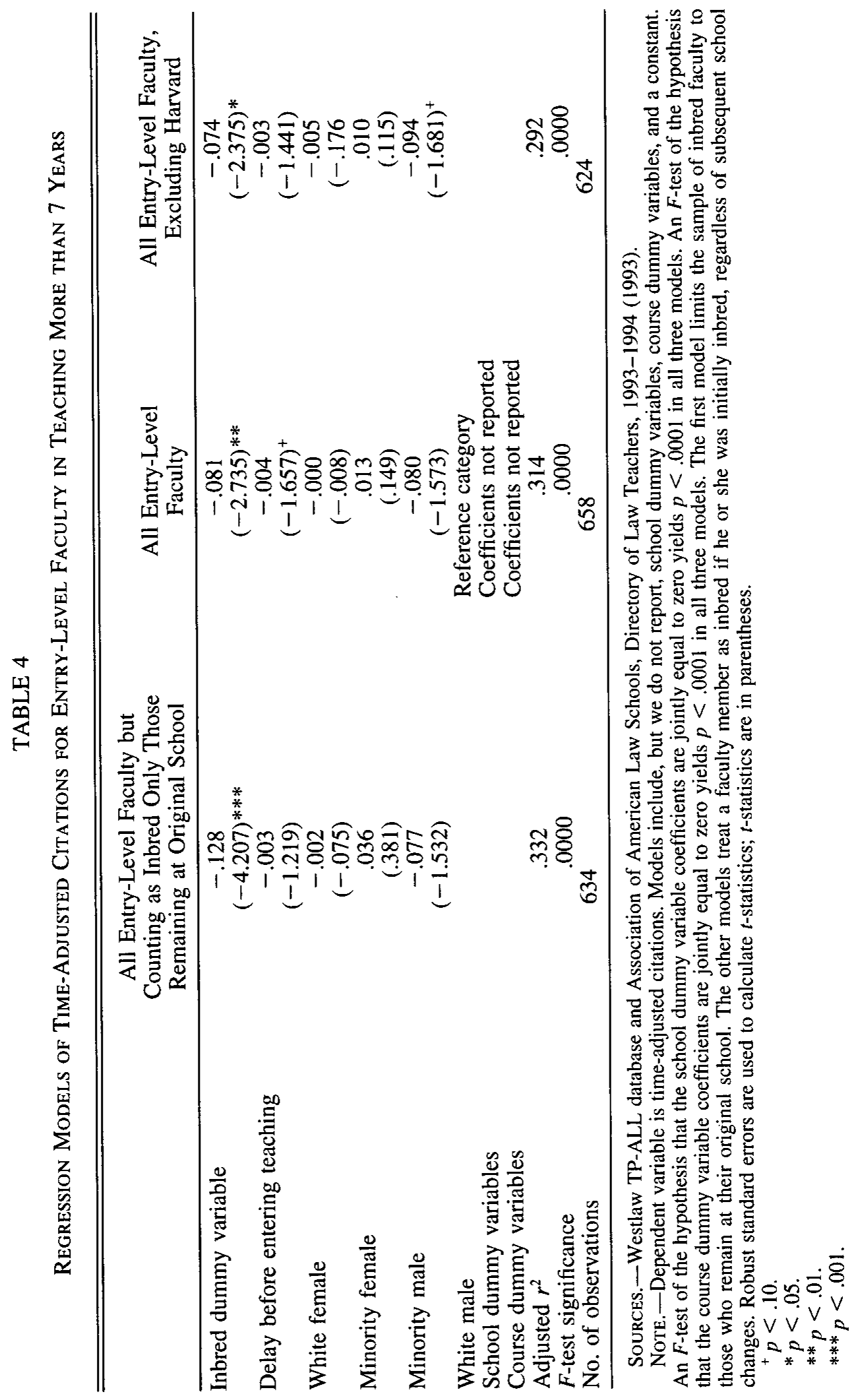




\section{Are Schools That Hire Their Own Graduates Selecting the Most Promising Scholars?}

So far we have compared inbred scholars with other entry-level scholars hired by the same school. Another metric is to compare inbred scholars with other entry-level scholars who graduated from the same school. For example, of recipients of a Harvard J.D. degree, are the faculty members hired by Harvard as inbreds outperforming the Harvard degree recipients hired by other schools?

This comparison makes sense only if the other schools at which a school's graduates have been hired are comparable to Harvard. That is, comparing graduates', not hires', performance requires some control to assure that the graduates have roughly equivalent credentials. One way to help assure such comparability is to limit the comparison to schools of comparable scholarly impact. They presumably do not have dramatically different hiring criteria.

Our previous work identifies a group of four law schools that has greater scholarly impact than any other: Yale, Chicago, Stanford, and Harvard. ${ }^{24}$ We refer to these as "Group 1" schools. We also identified a second group of comparable schools, as measured by scholarly impact, consisting of Berkeley, Columbia, Cornell, Michigan, Northwestern, NYU, and Virginia. A third group of comparable schools consists of Colorado, Duke, Georgetown, Illinois, Minnesota, Pennsylvania, Texas, UCLA, and USC. The second and third groups of schools are referred to as "Group 2" and "Group 3 " schools, respectively.

Together these three groups of schools account for the great majority, over 70 percent, of inbred hires in our sample. So we compare graduates of Yale, Chicago, Stanford, and Harvard hired by their J.D. degree schools with graduates of those four schools hired by the other three schools in Group 1. We compare graduates of the Group 2 schools hired by their J.D. schools with graduates of the Group 2 schools hired by the other six Group 2 schools. And we compare graduates of the Group 3 schools hired by their J.D. schools with graduates of the Group 3 schools hired by the other eight Group 3 schools. Table 5 presents the results.

For each of the three groups of schools, a law school's graduates hired at peer institutions (institutions in the same group) performed better, as measured by mean and median time-adjusted citations, than the law school's graduates hired by the law school itself. For the Group 1 schools, the difference between the medians is larger than the difference between the means. As measured by scholarly impact, schools are not necessarily

${ }^{24}$ Eisenberg \& Wells, supra note 2, at 387-92. 
TABLE 5

Time-Adjusted Citations of Inbred and Noninbred Entry-Level Faculty Members in Teaching More than 7 Years, by School Group

\begin{tabular}{|c|c|c|c|c|c|c|c|c|}
\hline \multirow[b]{2}{*}{ GROUP } & \multicolumn{4}{|c|}{$\begin{array}{l}\text { INBRED ENTRY-LEVEL } \\
\text { FACULTY MEMBERS }\end{array}$} & \multicolumn{4}{|c|}{$\begin{array}{l}\text { NONINBRED ENTRY-LEVEL } \\
\text { FACULTY MEMBERS }\end{array}$} \\
\hline & Mean & Median & $\begin{array}{c}\text { Standard } \\
\text { Deviation }\end{array}$ & $N$ & Mean & Median & $\begin{array}{c}\text { Standard } \\
\text { Deviation }\end{array}$ & $N$ \\
\hline 1 & 1.20 & 1.18 & .25 & 47 & 1.30 & 1.38 & .23 & 26 \\
\hline 2 & 1.03 & 1.09 & .29 & 46 & 1.06 & 1.11 & .21 & 23 \\
\hline 3 & .79 & .82 & .42 & 24 & .92 & .86 & .20 & 17 \\
\hline
\end{tabular}

SoURCES. - Westlaw TP-ALL database and Association of American Law Schools, Directory of Law Teachers, 1993-1994 (1993).

Note.-Group 1 schools are Yale, Chicago, Stanford, and Harvard. Group 2 schools are Berkeley, Columbia, Cornell, Michigan, Northwestern, NYU, and Virginia. Group 3 schools are Colorado, Duke, Georgetown, Illinois, Minnesota, Pennsylvania, Texas, UCLA, and USC. In each row, graduates of a school within a group are compared with graduates of that school teaching at other schools in the same group. For example, the inbred columns in the first row include graduates of Harvard teaching at Harvard (the inbred Harvard graduates), graduates of Chicago teaching at Chicago, graduates of Stanford teaching at Stanford, and graduates of Yale teaching at Yale. The noninbred columns in the first row include graduates of Harvard teaching at other (non-Harvard) Group 1 schools, graduates of Chicago teaching at other (non-Chicago) Group 1 schools, graduates of Stanford teaching at other (non-Stanford) Group 1 schools, and graduates of Yale teaching at other (non-Yale) Group 1 schools.

hiring their own best graduates when compared with the group of their graduates hired by comparable schools. The differences between inbred and noninbred faculty members at the Group 1 schools are nearly significant. ${ }^{25}$ The results for Groups 2 and 3 are not statistically significant.

To further explore the peer institution effect, we combine the data for the three groups in Table 5 and control for intergroup differences through school-group dummy variables. Table 6 reports models similar to those in Table 4. Time-adjusted citations is again the dependent variable. And we again control for delayed entry into teaching, school, race, sex, and courses taught in variables not reported here.

Two of the models in Table 6 confirm the significance or near significance of the inbred effect for graduates of particular schools. In the third model, which excludes Harvard, the effect is in the same direction but is less strong and not statistically significant. The Group 1 and Group 2 dummy variables behave as expected and show significantly more citations to faculty members in these groups than to faculty members at Group 3 schools.

${ }^{25}$ A $t$-test yields a $p$-value of .103 , and a Mann-Whitney test yields a $p$-value of .052 . 


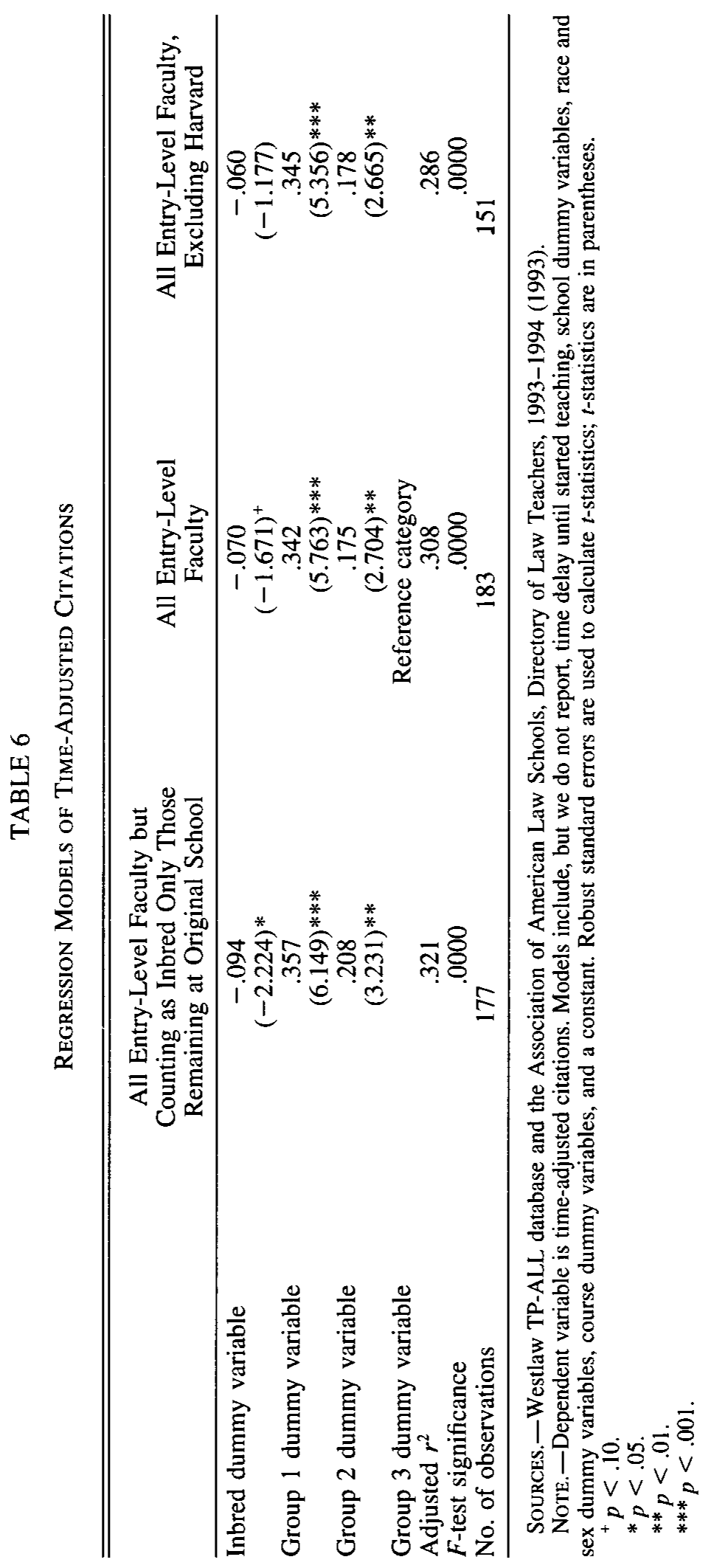




\section{E. Explaining the Results}

Faculties may be hiring for features other than potential scholarly impact when they hire their own graduates. Perhaps these hires are sought more for their teaching potential. But some find that a positive correlation exists between teaching performance and scholarly performance ${ }^{26}$ and there is little evidence of a negative correlation. ${ }^{27}$ Available data thus do not support the need to sacrifice one to achieve the other or to use inbred hires as a special source of potentially excellent teachers.

A simpler explanation for the inbred effect is suggested by Deborah Jones Merritt and Barbara F. Reskin's comprehensive study of law school hiring. They find that, as measured by objective criteria, inbreds have inferior credentials compared with noninbreds. ${ }^{28}$ And the effect that they detect is massive. They found inbred status to be by far the strongest predictor of being hired at a prestigious law school. Being inbred enhanced the odds "of appointment at a top sixteen institution by a factor of more than fiftyfive." ${ }^{29}$ Since their study controlled for the prestige of J.D. institution, among other factors, the relation between inbred status and being hired by a prestigious law school "does not simply reflect the preference of all law schools for graduates of the top institutions." ${ }^{30}$ In short, available evidence indicates that schools hire inbreds with credentials that are inferior to those of noninbreds. This could well lead to inferior performance.

The inferior performance and credentials of inbred faculty must have their roots in the inability of faculty members to evaluate their own graduates as objectively as they evaluate other schools' graduates. We have more information yet fail to produce a better set of hires. Why might this be? Three kinds of reasons are worth separating.

First, faculty members may be too close to their own school's graduates to judge them well. Inbred candidates often will have served as research assistants for professors, performed well in class, performed well on student publications, and otherwise impressed faculty members. Just as people are unlikely to provide objective evaluations of their children, faculty members may be too close to judge some students well. And, almost as an axiom, not only will inbred hires be a group of students who have performed well in law school tasks but also faculty members will like them as people. We

\footnotetext{
${ }^{26}$ James Lindgren \& Allison Nagelberg, Are Scholars Better Teachers? 73 Chi.-Kent L. Rev. 823 (1998).

${ }^{27}$ Merritt, supra note 21, at 767.

${ }^{28}$ Merritt \& Reskin, supra note 1, at 238-40.

${ }^{29}$ Id. at 243.

${ }^{30}$ Id.
} 
tend not to push hard to hire people we dislike. And faculty members may be less able to assess the performance of people they like.

Second, intentionally or not, inbred hires are likely to have appealed to faculty members' own high opinions of their own works. Inbreds may well be writing in the areas in which mentoring faculty work, even building on their works, thereby enhancing the faculty member's own scholarly importance. We are unlikely to evaluate harshly those who take most seriously what we do and even emulate what we do. Imitation is not only the sincerest form of flattery, it is the highest form of evidence of the quality of the imitator.

A third set of reasons focuses not on credentials or on faculty hiring performance but on the posthire performance of inbred hires. The inability of schools to hire their best graduates, even when compared only with graduates at peer institutions, is so surprising that we suspect more is going on than mere blundering at the hiring stage. Some inbred faculty members are protegees of mentors. When we hire our own protegees, they may have less to say that is new than the average noninbred faculty hire. Protegees may be laboring in fields dominated by their faculty mentors and find it difficult to add innovative contributions. However well received the protegee's contributions may be by their mentors, the outside world may view them as second-level performers in their chosen area. Mentors are difficult to displace. The inbred hire may come with more baggage than a noninbred hire. He or she may feel indebted to a mentor or group of mentors and be especially reluctant to challenge the mentors' view of the law and the world. This understandable reluctance could produce less-innovative scholarship.

\section{CONCLUSION}

The willingness of strong law schools to offer initial teaching jobs to their own graduates contrasts with the practice of many strong departments in nonprofessional schools. Those departments require their own graduates to prove themselves elsewhere before offering them teaching positions. We present evidence that the doctoral programs have a solid basis for their rules. By our measure of performance (scholarly impact as measured by citation frequency), inbred law school faculty members do not perform as well as noninbred faculty members. 